\title{
Detection and Characterization of Circulating Tumor Associated Cells in Metastatic Breast Cancer
}

\author{
Zhaomei Mu ${ }^{1, *}$, Naoual Benali-Furet ${ }^{2}$, Georges Uzan ${ }^{2}$, Anaëlle Znaty ${ }^{2}$, Zhong Ye ${ }^{3}$, \\ Carmela Paolillo ${ }^{4}$, Chun Wang ${ }^{3}$, Laura Austin ${ }^{3}$, Giovanna Rossi ${ }^{1}$, Paolo Fortina 4,5, \\ Hushan Yang ${ }^{3}$ and Massimo Cristofanilli ${ }^{1, *}$ \\ 1 Department of Medicine-Hematology and Oncology, Robert H Lurie Comprehensive Cancer Center, \\ Feinberg School of Medicine, Northwestern University, Chicago, IL 60611, USA; giovirossi85@yahoo.it \\ 2 ScreenCell SA, Sarcelles 95200, France; benali@screencell.com (N.B.-F.); guzan@screencell.com (G.U.); \\ aznaty@screencell.com (A.Z.) \\ 3 Department of Medical Oncology, Sidney Kimmel Cancer Center, Thomas Jefferson University, \\ Philadelphia, PA 19107, USA; Zhong.Ye@jefferson.edu (Z.Y.); Chun.Wang@jefferson.edu (C.W.); \\ laustin@gmail.com (L.A.); hushan.yang@jefferson.edu (H.Y.) \\ 4 Department of Cancer Biology, Sidney Kimmel Cancer Center, Thomas Jefferson University, \\ Philadelphia, PA 19107, USA; carmela.Paolillo@jefferson.edu (C.P.); paolo.Fortina@jefferson.edu (P.F.) \\ 5 Department of Molecular Medicine, University of Rome "Sapienza", Rome 00185, Italy \\ * Correspondence: zhaomei.mu@northwestern.edu (Z.M.); massimo.cristofanilli@nm.org (M.C.); \\ Tel.: +1-312-503-5489 (Z.M.); +1-312-503-5488 (M.C.)
}

Academic Editor: Dario Marchetti

Received: 5 August 2016; Accepted: 23 September 2016; Published: 30 September 2016

\begin{abstract}
The availability of blood-based diagnostic testing using a non-invasive technique holds promise for real-time monitoring of disease progression and treatment selection. Circulating tumor cells (CTCs) have been used as a prognostic biomarker for the metastatic breast cancer (MBC). The molecular characterization of CTCs is fundamental to the phenotypic identification of malignant cells and description of the relevant genetic alterations that may change according to disease progression and therapy resistance. However, the molecular characterization of CTCs remains a challenge because of the rarity and heterogeneity of CTCs and technological difficulties in the enrichment, isolation and molecular characterization of CTCs. In this pilot study, we evaluated circulating tumor associated cells in one blood draw by size exclusion technology and cytological analysis. Among 30 prospectively enrolled MBC patients, CTCs, circulating tumor cell clusters (CTC clusters), CTCs of epithelial-mesenchymal transition (EMT) and cancer associated macrophage-like cells (CAMLs) were detected and analyzed. For molecular characterization of CTCs, size-exclusion method for CTC enrichment was tested in combination with DEPArray ${ }^{\mathrm{TM}}$ technology, which allows the recovery of single CTCs or pools of CTCs as a pure CTC sample for mutation analysis. Genomic mutations of TP53 and ESR1 were analyzed by targeted sequencing on isolated 7 CTCs from a patient with MBC. The results of genomic analysis showed heterozygous TP53 R248W mutation from one single CTC and pools of three CTCs, and homozygous TP53 R248W mutation from one single CTC and pools of two CTCs. Wild-type ESR1 was detected in the same isolated CTCs. The results of this study reveal that size-exclusion method can be used to enrich and identify circulating tumor associated cells, and enriched CTCs were characterized for genetic alterations in MBC patients, respectively.
\end{abstract}

Keywords: metastatic breast cancer (MBC); circulating tumor associated cells; circulating tumor cells (CTCs); circulating tumor cell clusters (CTC clusters); epithelial-mesenchymal transition (EMT); cancer associated macrophage-like cells (CAMLs); size-exclusion technology 


\section{Introduction}

Breast cancer is the most common cancer in women and metastasis is the major cause of the mortality of patients [1]. The treatment for aggressive metastatic breast cancer (MBC) remains challenging as the intrinsic clinical subtypes, biological features of the metastases, and tumor heterogeneity including circulating tumor cells (CTCs) all contribute to the resistance to current standard strategies [2]. Current treatments mainly rely on expression profiles of the primary tumor or metastatic tumor biopsy. However, the expression profiles may change during or after adjuvant treatments or targeted therapies. A real-time tumor assay using a liquid biopsy that focuses on the analysis of CTCs and circulating tumor DNA (ctDNA) has been actively investigated as new therapeutic targets and drug resistance mechanisms in cancer patients [3,4]. Blood-based testing using a non-invasive and complementary approach has the potential to enhance therapeutic efficacy and improve the outcome of MBC patients.

Circulating tumor cells are rare cells that are shed into bloodstream from primary or metastatic tumors with the potential to initiate tumor metastasis in distant organs $[5,6]$. The enumeration of CTCs can provide consistent prognostic values in MBC patients [7,8]. The semi-automated CellSearch ${ }^{\circledR}$ platform (Janssen Diagnostics, Raritan, NJ, USA) is the only FDA-approved platform for CTC detection and enumeration based on the expression of epithelial cell adhesion molecule (EpCAM) [7-10]. EpCAM-based assay is unable to detect CTCs with low or absent EpCAM expression and other circulating tumor associated cells, including stem cell-like tumor cells and CTCs undergoing epithelial-mesenchymal transition (EMT), which were identified by stem cell and EMT markers in early and metastatic breast cancer patients [11-13]; and cancer associated macrophage-like cells (CAMLs), which are specialized phagocytic myeloid cells found in the peripheral blood of patients with solid tumors including breast cancer, but not in healthy individuals [14]. CellSearch and other EpCAM-based assays may miss the detection of these cells.

Due to the limitation of EpCAM-based capture assays for the detection of various circulating tumor associated cells, many other technologies have been developed including size-execution enrichment devices [15]. ScreenCell ${ }^{\circledR}$ technology is a range of specific devices and has been validated for the detection and molecular analysis of CTCs in several other solid tumors including prostate, pancreatic cancer, renal, colon, and lung [16-21]. Without surface-marker selection, size-execution method allows the capture of all types of circulating tumor associated cells in one blood draw and exploring the phenotypic and genetic heterogeneity of these cells.

Molecular characterization of CTCs is important to confirm their malignant origin and to identify the genomic abnormalities that may be undetectable or different from the primary tumor during disease progression and therapy resistance in order to achieve individual patient management and treatment. CTCs are rare and very heterogeneous populations of tumorigenic cancer cells in the blood of patients with metastatic cancer, which makes their isolation and characterization challenging. Isolation of pure CTCs from pre-enriched blood samples is a key step for exploring accurate genomic analysis. The DEPArray ${ }^{\mathrm{TM}}$ technology (Silicon Biosystems, San Diego, CA, USA) is the ideal system to collect pure CTCs for further molecular characterization. Recent studies showed a workflow that enables isolation and molecular characterization at single CTCs, which highlight the potential clinical utility for diagnostic molecular profiling in precision medicine [22-24]. The CTCs have been enriched from large population of red blood cells (RBCs) and white blood cells (WBCs) before single-cell sorting processing with DEPArray ${ }^{\mathrm{TM}}$ technology. CellSearch enrichment is the current commonly used method for DEPArray single-cell sorting.

In this pilot study, we aim to detect and validate circulating tumor associated cells including CTCs, CTC clusters, EMT CTCs, and CAMLs in one blood draw for MBC patients. In addition, we aim to explore the applicability of a protocol for the molecular characterization of pure CTCs by size exclusion enrichment method followed by single-cell sorting using the DEPArray ${ }^{\mathrm{TM}}$ in one patient blood sample. We target to analyze TP53 and ESR1 mutations based on the mutations data found in the corresponding patient's tumor tissue sample. 


\section{Results}

\subsection{Detection of Circulating Tumor Associated Cells}

Thirty patient blood samples were processed for the evaluation of CTCs and CTC clusters in this study. The morphological phenotypes of CTCs and CTC clusters are highly heterogeneous with cytokeratin (CK) positive staining variations in shape, size and degree of expression. Representative images from three patient samples are illustrated in Figure 1A. CTC-clusters were composed of two or more individual CTCs containing distinct nuclei bound together, and with intact cytoplasm membranes that distinguish the background staining from leukocyte marker CD45 staining. Among the 30 patients, CTCs were detected in $20(66.7 \%)$ patients with a range from 1 to 347 , and eight $(26.7 \%)$ patients had at least one identified CTC clusters ( $\geq 2$ CTCs) with a range from 1 to 10 (Table 1). CTCs represent very heterogeneous populations of tumorigenic cancer cells in MBC patient and some subpopulations had undergone EMT, which expressed decreased level or absence of epithelial markers including EpCAM. In order to characterize EMT phenotype on the captured CTCs, the immunostaining was performed with anti-Vimentin or $\mathrm{N}$-Cadherin antibodies. EMT CTCs were identified as positive staining for Vimentin-Fluorescein isothiocyanate (FITC) or N-Cadherin-FITC, the representative images are shown in Figure 1B. In 28 processed patient samples, $13(46.4 \%)$ patients had at least one detected positive either Vimentin or $\mathrm{N}$-Cadherin positive CTCs (Table 1). Recent studies showed that CAMLs were found in blood of cancer patient and their presence was associated with the stage of disease as a blood based biomarker [14]. In this study, we detected CAMLs in MBC patient blood samples using May-Grunwald Giemsa (MGG) combined to immunofluorescence staining (Figure 1C). Like the CTCs, CAMLs are morphological heterogeneous in size ranges, shape, nuclear profiles. CAMLs express diffused cytoplasmic cytokeratin and CD45-positive signals. The results were consistent with previous observation [14], in which CAMLs express myeloid lineage $\left(\mathrm{CD} 14^{+} / \mathrm{CD} 11 \mathrm{c}^{+}\right), \mathrm{CD} 45^{+}$, and both cytokeratin and EpCAM epithelial markers. Among the tested 20 patient samples, 15 (75\%) patients had at least one detected CAMLs by either MGG or immunofluorescence staining (Table 1). Together, our results demonstrated that circulating tumor associated cells can be efficiently captured and enriched by the size-exclusion method for the cytological analysis, and a comprehensive test including multiple markers in one blood draw is necessary to explore the heterogeneity.

Table 1. Summary of CTCs, CTC-clusters, EMT CTCs, and CAMLs detected in MBC patients.

\begin{tabular}{ccc}
\hline Circulating Tumor Associated Cells & Total Patients (N) & Positive Patients (\%) \\
\hline CTCs $\geq 1$ & 30 & $20(66.7)$ \\
CTC clusters $\geq 2$ CTCs & 30 & $8(26.7)$ \\
EMT CTCs $\geq 1$ & 28 & $13(46.4)$ \\
CAMLs $\geq 1$ & 20 & $15(75.0)$ \\
\hline
\end{tabular}

$\mathrm{MBC}$, metastatic breast cancer; CTCs, circulating tumor cells; CTC clusters, circulating tumor cell clusters; EMT, Epithelial-mesenchymal transition; CAMLs, cancer associated macrophage-like cells.

\subsection{Enrichment, Single-Cell Sorting and Genome Amplification of Circulating Tumor Cells (CTCs)}

To achieve the molecular characterization of the pure CTCs, a combined procedure is needed. The proposed workflow included several steps of CTC enrichment, single-cell sorting, and whole genome amplification (WGA) for sequencing is outlined in the Materials and Methods (Figure 2). One MBC patient sample SKM00447 was processed for the combined procedure. CTC enrichment from $3 \mathrm{~mL}$ of blood was first performed using ScreenCell ${ }^{\circledR}$ Cyto devices followed by immunofluorescence staining using anti-CK, DAPI and anti-CD45 antibodies. Forty-six CTCs $/ 3 \mathrm{~mL}$ of blood were identified with one additional device and immunostained CTCs. Ten single CTCs and four single WBCs with good images were identified and isolated on DEPArray ${ }^{\mathrm{TM}}$ system (Figure 3A). Single CTCs and pools of CTCs (two or three cells) were subjected to the WGA using Ampli1 WGA kit. Genome integrity was 
confirmed by PCR with the presence of short, medium, and long DNA fragments. Representative gel image from DNA amplification in some CTCs is shown in Figure 3B.

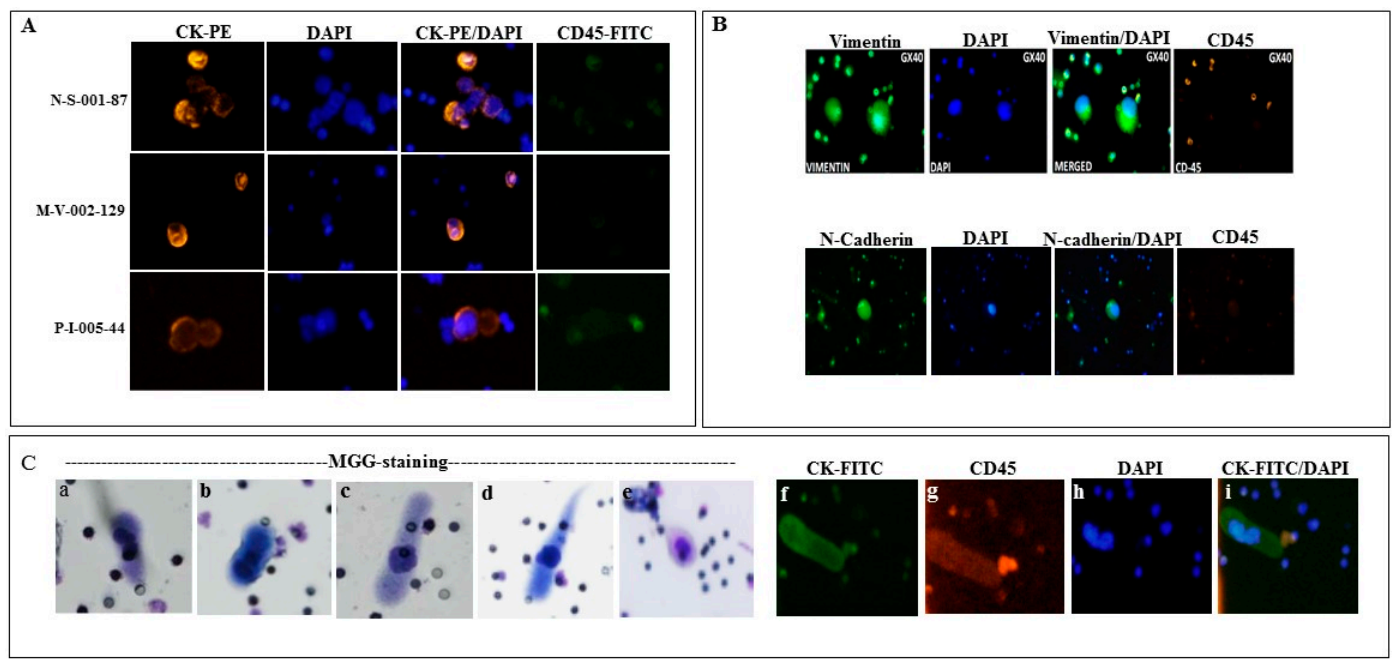

Figure 1. Detection of circulating cancer associated cells in metastatic breast cancer (MBC): (A) Representative immunostaining images from three patient samples with identifications (N-S-001-87, M-V-002-129, P-I-005-44) showing circulating tumor cells (CTCs) and CTC clusters with cytokeratin (CK) and 4',6-diamidino-2-phenylindole (DAPI) positive and CD45 negative staining; (B) Immunostaining of epithelial-mesenchymal transition (EMT) CTCs showed mesenchymal markers Vimentin or $\mathrm{N}$-Cadherin positive; (C) Representative images of cancer associated macrophage-like cells (CAMLs) from MGG (May-Grunwald Giemsa) and immunostaining, cytological phenotypes as: spindle-shaped $(\mathbf{a}, \mathbf{d})$; round $(\mathbf{b}, \mathbf{e})$; oblong $(\mathbf{c})$; cytokeratin positive (f); CD45 positive (g); DAPI (h); and composite image of CK and DAPI (i). The images were acquired on microscope at $40 \times$ magnification.

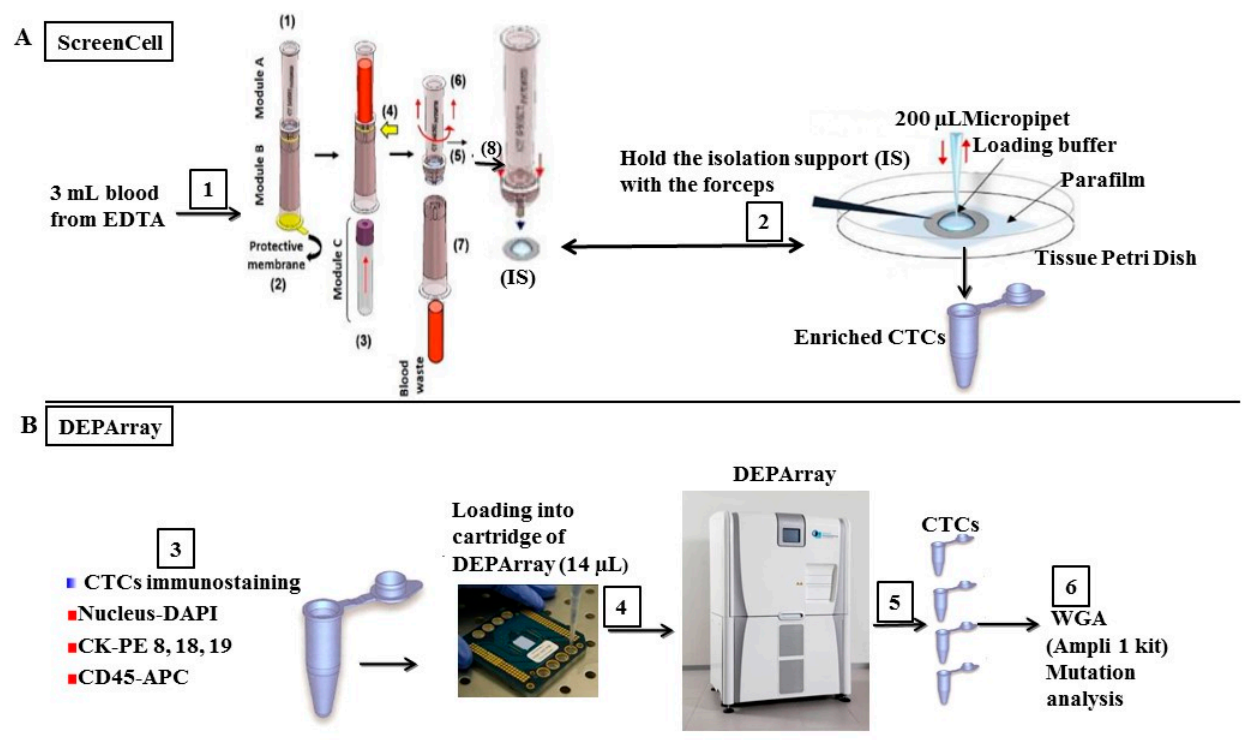

Figure 2. Overall processing workflow of blood sample on: ScreenCell ${ }^{\circledR}$ Cyto device (A); and DEPArray ${ }^{\mathrm{TM}}$ platform (B). Step 1: $3 \mathrm{~mL}$ of blood was processed; Step 2: Cell suspension was recovered from the IS and transferred into $1.5 \mathrm{~mL}$ of Lo-bind eppendorf tube; Step 3: Enriched cells were stained by a manual staining procedure; Step 4: Cells were resuspended in a final volume of $14 \mu \mathrm{L}$ and loaded in a DEPArray cartridge; Step 5: Sorting procedures were performed and single cells or pools of cells were isolated on DEPArray ${ }^{\mathrm{TM}}$ platform; Step 6: Isolated cells were subjected to WGA using the Ampli1 WGA kit and mutation analysis. 
A

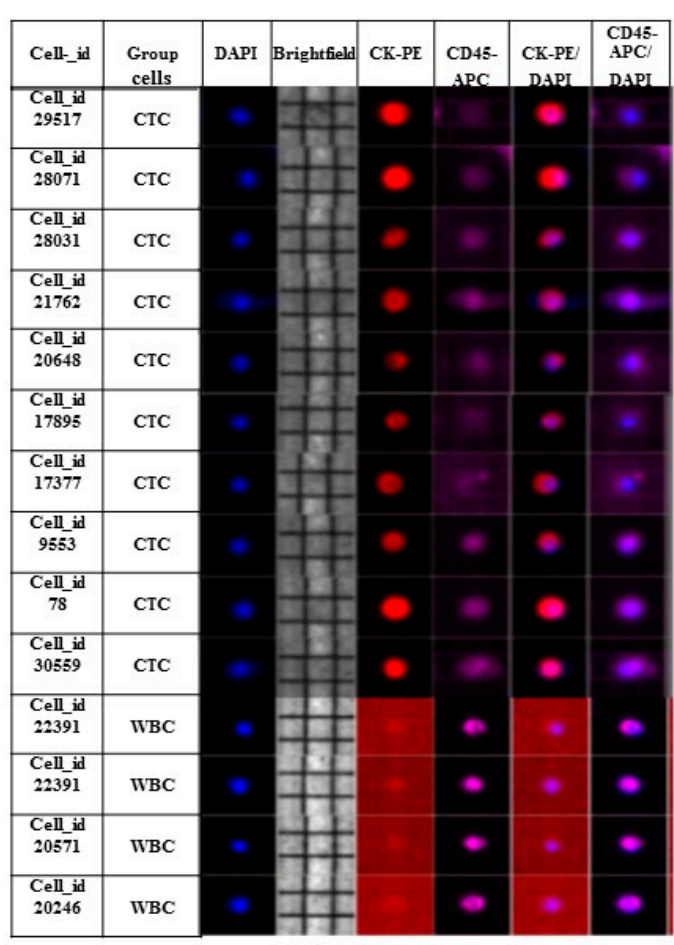

B

C

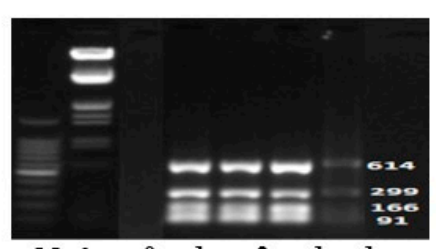

Markers $0 \underset{\text { WBC }}{1}-2 \underset{C T C s}{2}-1$

TP53 exon $6248 \mathrm{~W}$ mutation

R248, c. $742-744$ R248W, c.742C $>\mathrm{T} \quad$ R248W, c.742C $>\mathrm{T}$

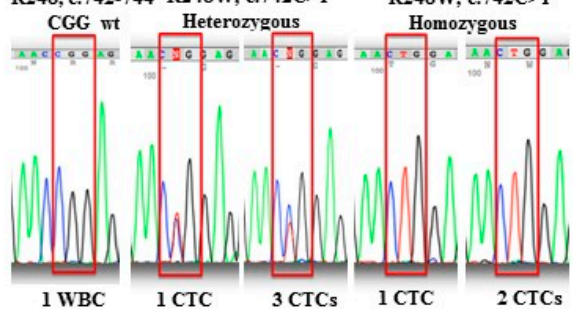

D

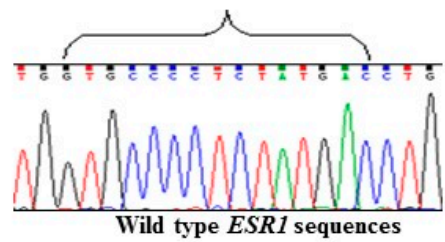

Figure 3. Genomic characterization of isolated CTCs. (A) Composite images visualized on the DEPArray ${ }^{\mathrm{TM}}$ platform after ScreenCell Cyto enrichment showing single CTCs $\left(\mathrm{CK}-\mathrm{PE}^{+} / \mathrm{DAPI}^{+}\right)$and WBCs (CD45-APC ${ }^{+} / \mathrm{DAPI}^{+}$); (B) Gel images of Ampli1 quality control (QC) PCR products from CTCs and WBC showing the genome integrity with the presence of short, medium and long DNA fragments; (C) The TP53 exon 6 R248W mutations were detected in single CTCs and pools of CTCs, wild-type sequences in single WBC; (D) Wild-type ESR1 sequences were detected in all isolated CTCs.

\subsection{Mutation Analysis of TP53 and ESR1 in Isolated CTCS}

The patient SKM00447 was metastatic inflammatory breast cancer with estrogen receptor (ER)-positive, progesterone receptor (PR)-negative, and HER2/neu-negative treated with multiple lines of systemic therapy, including endocrine therapy and combination chemotherapy. The mutation analysis of tumor tissue sample using commercially available NGS testing (FoundatioOne ${ }^{\circledR}$, Foundation Medicine, Cambridge, MA, USA) showed that the tumor harbored TP53 exon 6 R248W missense point mutation. Based on these clinical information, we analyzed single and pooled CTCs on the mutation status of TP53 and ESR1, which is activating estrogen receptor1 and its mutation was associated with the resistance to endocrine therapy [25]. Interestingly, heterozygous TP53 exon 6 R248W mutation was detected in one single CTC and pools of three CTCs, and homozygous TP53 exon 6 R248W mutation was found in one single CTC and pools of two CTCs; one single WBC as control displayed the wild-type TP53 sequence in exon 6 R248 (Figure 3C). The results suggest the heterogeneity of TP53 mutations within the CTCs isolated even from same patient sample, and mutation profile of CTCs was consistent with the corresponding patient's tumor tissue. In the same isolated CTCs, the most common mutations in exon 8 (c.1607-1621) of ESR1 were not detected, the results showed same wild-type ESR1 sequence from all CTCs (Figure 3D). ESR1 mutation was also not found in this patient's primary tumor test.

Overall, we demonstrated the applicable workflow using size-exclusion approach to enrich CTCs for pure CTC sorting on DEPArray ${ }^{\mathrm{TM}}$ platform and further molecular characterization analysis. 


\section{Discussion}

CTC enumeration demonstrated a significant prognostic value, and additional blood based markers may also play roles in furthering prognostic and predictive values in MBC. Molecular characterization of CTCs can help determine the efficacy of selected therapeutic targets. In this pilot study, we isolated and analyzed multiple circulating tumor associated cells including CTCs, CTC clusters, EMT CTCs, and CAMLs by combining size-exclusion enrichment and cytological analysis in MBC patients. The CTCs can be efficiently enriched by size-exclusion method for further use in pure single-cells sorting on DEPArray ${ }^{\mathrm{TM}}$ platform. Mutational analysis of the isolated CTCs revealed a heterogeneous TP53 mutation in one MBC patient.

The CellSearch ${ }^{\mathrm{TM}}$ system is the only CTC enumeration platform FDA-cleared and used in the clinical management of metastatic patients. Unfavorable prognostic outcome was determined based on a cut-off of $\geq 5$ CTCs per $7.5 \mathrm{~mL}$ of blood in MBC [7-10]. However, there are no additional further prognostic markers in patients with $\geq 5$ CTCs. Recent studies by our group and others have shown that the presence of CTC clusters when CTCs were enumerated at the same analyzing time on the CellSearch system might provide additional prognostic values over CTC enumeration alone for MBC patients [26-28]. The CTC clusters have shown much higher metastatic potential than single CTCs in breast cancer [27]. There is increasing evidence suggesting that EMT is involved in the metastatic process and drug resistance in breast cancer [29]. Clinical studies shown that EMT markers were detected in CTCs from early and metastatic breast cancer patients [13,30,31]. Despite these observations, very few studies have been able to demonstrate the independent prognostic value of EMT CTCs in MBC [32,33]. Currently, there are no standard reference markers and approved methods for the selection and detection of EMT CTCs. EpCAM-based assay is unable to capture EMT CTCs due to the loss of epithelial features in those cells, but CTCs expressing EMT and epithelial markers can be detected in breast cancer patients using the size-exclusion enrichment method [30,31]. Our results showed that all CTCs, CTC clusters and EMT CTCs can be detected and identified in the peripheral blood of MBC patients using the size-exclusion method. Additional studies in a larger number of patients are required to validate more EMT markers and the prognostic value in MBC.

Another potential blood-based biomarker for solid tumors are CAMLs. Recent studies have shown that the presence of CAMLs may be associated with malignant diseases and activation of innate immunity in cancer patients [14,34]. The detection of CAMLs may differentiate malignant disease and benign breast lesions as described in a recent report [35]. However, the function and prognostic value of CAMLs and the role in activation of innate immunity in cancer patients remain unknown. Consistent with previous findings, CAMLs were detected in 15 (75\%) patients among $20 \mathrm{MBC}$ patients and showed a considerable heterogeneity in the phenotypes. Given the larger size of CAMLs, size-exclusion methods may offer a significant advantage for capturing these cells. Further molecular and functional validation of CAMLs in larger numbers of patients will open a path to comprehensive blood-based biomarker access.

A recent clinical trial showed that CTC enumeration alone was not sufficient to guide chemotherapeutic treatment change for survival benefits in MBC [36], which highlights the importance of CTC molecular characterization to be more informative for the choice of treatment options. Monitoring CTC characterization over a period of time seems necessary since marker profiles can change during the course of therapy and disease progression. For the first time, we tested the feasibility that CTCs were enriched using the size-exclusion method and followed by DEPArray ${ }^{\mathrm{TM}}$ isolation to achieve mutation analysis on the single cell or pools of CTCs in one MBC patient sample. CTCs showed the matched TP53 R248W mutation with the patient's tissue tumor although a heterogeneity within CTCs. The results from one recent study showed the extreme heterogeneity of the mutational status of single CTCs in metastatic breast cancer patients [23], there is also a discordance between the mutational status of the primary tumor and CTCs among three analyzed patients. Enriched CTCs using the CellSearch method followed by DEPArray ${ }^{\mathrm{TM}}$ sorting for the molecular profiling of single CTCs has been recently reported [22-24]. Here, we present the size-exclusion method with high efficacy, low-cost, 
and flexibility to enrich CTCs. The method has a potential advantage for EMT CTCs and CAMLs enrichment to achieve the molecular profiling analysis in single cells or pure population of cells by combining DEPArray ${ }^{\mathrm{TM}}$ technology.

In summary, our data suggest that blood-based method using multiple markers analysis and molecular characterization of CTCs can be achieved by a combined method. Along with the further evaluation of association with patient outcomes, more studies with larger sample size and longer follow-up are warranted to confirm these findings and explore their clinical value. The comprehensive analysis from one blood draw as a non-invasive approach holds promise in clinical applicability for future personalize treatment of MBC patients.

\section{Materials and Methods}

\subsection{Study Patients}

Female MBC (stage IV) patients were identified from a clinic-based cohort of breast cancer patients who visited the Breast Care Center at the Sidney Kimmel Cancer Center at Thomas Jefferson University Hospital (Philadelphia, PA, USA). MBC diagnosis was based on tissue histology, complemented by radiological evaluations. This study was approved by the Office of Human Research, Division of Human Subjects Protection, Institutional Review Board (IRB) of Thomas Jefferson University Hospital (October 2013, protocol \#13P.302). Written informed consent was obtained from all patients before blood samples were collected.

\subsection{Blood Sample Collection and Processing}

Approximately $8 \mathrm{~mL}$ of whole blood was collected in K2EDTA vacutainers or Transfix tubes and kept at room temperature. All samples were processed within $4 \mathrm{~h}$ (K2EDTA tubes) or $72 \mathrm{~h}$ (Transfix tubes) of being drawn. CTCs were captured on the isolation support (IS) using size-exclusion Cyto devices according to the manufacturer's instruction (ScreenCell, Sarcelles, France) as previously described [16]. The ScreenCell ${ }^{\circledR}$ device is holding an IS with $18-\mu \mathrm{m}$-thick polycarbonate membrane with circular pores $(6.5 \pm 0.33 \mu \mathrm{m})$ that are randomly distributed throughout membrane and a detachable nozzle attached to it. This nozzle guides the insertion of a collection tube to it to gently vacuum the blood through the IS, leaving the CTCs on the IS. The process is quick ( $3 \mathrm{~min}$ ) [16]. Briefly, $3 \mathrm{~mL}$ of blood was mixed with $4 \mathrm{~mL}$ of ScreenCell ${ }^{\circledR}$ FC2 dilution buffer and incubated for $8 \mathrm{~min}$ at room temperature. After incubation, diluted blood was passed through the ScreenCell Cyto device by vacuum force, and IS was rinsed by adding $1.6 \mathrm{~mL}$ of Phosphate Buffered Saline (PBS). After the enrichment, the IS was disassembled from the ScreenCell device, and allowed to air dry. The dried IS was stored at 4 or $-20^{\circ} \mathrm{C}$ until further cytological analysis. Two ISs were collected for each patient sample.

\subsection{Cytological Analysis}

For cytological evaluation, the IS was rehydrated with Tris-buffered saline (TBS) and subjected to standard MGG (May-Grunwald Giemsa) staining with May Grunwald dye and Giemsa (EMD Millipore, Billerica, MA, USA). Stained IS was evaluated based on the cytomorphological features under light microscope. MGG stained IS can be reused for further immunofluorescence staining after removing MGG staining by washing the IS with TBS containing $0.05 \%$ Tween 20 (TBST) for $20 \mathrm{~min}$ at room temperature (RT). Identification of CTCs and CTC clusters were determined based on the immunofluorescence staining of phycoerythrin (PE)-conjugated cytokeratins (CK-8, 18 and 19), DAPI (4' ,6-diamidino-2-phenylindole) (CellSearch ${ }^{\circledR}$ CTC kits, Janssen Diagnostics), and CD45-FITC antibodies (clone HI30, Biolegend, San Diego, CA, USA). In brief, the IS was rehydrated with TBS and permeabilized with TBS containing $0.2 \%$ Triton X-100. After blocking with $3 \%$ BSA (bovine serum albumin) for $30 \mathrm{~min}$, the IS was stained with CK-PE and CD45-FITC for $45 \mathrm{~min}$, and then DAPI for 5 min at RT. For EMT CTCs identification, the IS was stained with Vimentin-FITC (Santa 
Cruz Biotechnology, Santa Cruz, CA, USA) and N-Cadherin (eBioscience, San Diego, CA, USA) followed by Alexa Fluor 647 donkey anti-mouse antibody. The stained IS was viewed and images of stained cells were captured on Olympus BX43 Fluorescence Digital Imaging System or NIKON Eclipse 80i microscope. Positive CTCs were identified based on staining for both CK and DAPI positive, and for $\mathrm{CD} 45$ negative $\left(\mathrm{CK}^{+} / \mathrm{DAPI}^{+} / \mathrm{CD} 45^{-}\right)$. CTC clusters showed as a group of two or more individual CTCs containing distinct nuclei and intact cytoplasm membranes as previously described [26]. EMT positive CTCs were identified by positive staining for Vimentin or $N$-Cadherin and DAPI, and negative staining for CD45 $\left(\right.$ Vimentin $^{+}$or $\mathrm{N}$-Cadherin ${ }^{+} / \mathrm{DAPI}^{+} / \mathrm{CD}^{4} 5^{-}$). CAMLs were identified by MGG or immunofluorescence staining by CK-FITC.

\subsection{CTCs Enrichment and Single-Cell Sorting by DEPArray ${ }^{\mathrm{TM}}$ System}

CTCs were first enriched using ScreenCell Cyto devices and then sorted on DEPArray ${ }^{\mathrm{TM}}$ (Silicon Biosystems) system for collecting single CTCs or pools of CTCs. The overall experimental workflow is illustrated in Figure 2. CTCs enrichment was performed as described above and the single-cell sorting was conducted according to the manufacturer's instruction for DEPArray ${ }^{\mathrm{TM}}$ analysis. Briefly, diluted blood ( $3 \mathrm{~mL}$ of blood mixed with $4 \mathrm{~mL}$ of FC2 dilution buffer) was passed through the hydrated IS of ScreenCell Cyto device with loading Buffer (PBS containing 3\% BSA and 5 mM EDTA). The IS was covered with a drop of loading buffer after cell enrichment and was released from the device onto the pertri dish containing parafilm foil. The cells on the IS were detached by pipetting the liquid for several times and transferred into $1.5 \mathrm{~mL}$ of Lo-bind eppendorf tube. The recovering process was repeated by adding the loading buffer as necessary. The cells were centrifuged at $400 \times g$ for $10 \mathrm{~min}$ at RT and the supernatant was carefully removed. The cell pellets were reconstituted in TBS and proceeded to immunofluorescence staining by CK-PE, CD45-APC and DAPI (CellSearch ${ }^{\circledR}$ CTC kits, Janssen Diagnostics). Enriched CTCs were then sorted on DEPArray ${ }^{\mathrm{TM}}$ platform (Figure 2). In brief, both $800 \mu \mathrm{L}$ of SB115 buffer (Silicon Biosystems) and $14 \mu \mathrm{L}$ of sample in SB115 buffer were loaded on the DEPArray ${ }^{\mathrm{TM}}$ cartridge chip (DEPArray ${ }^{\mathrm{TM}}$ A300K-cartridge, Silicon Biosystems). The chip was scanned in first step, and images of cells were captured and processed for selecting CTCs and WBCs based on CK-PE/DAPI positive staining for CTCs or CD45-APC/DAPI positive staining for WBCs as control. At final step, single CTCs or pools of CTCs, and single WBCs as control were recovered into individual $200 \mu \mathrm{L}$ of PCR tubes. The samples were centrifuged at $14,000 \times g$ for $10 \mathrm{~min}$ and washed once with $100 \mu \mathrm{L}$ of PBS. The buffer was removed from the tube and the cell pellets in $1-2 \mu \mathrm{L}$ volume were proceeded to whole genome amplification (WGA) or stored at $80^{\circ} \mathrm{C}$ until further WGA.

\subsection{Ampli1 ${ }^{\mathrm{TM}}$ Whole Genome Amplification and Quality Control Assays}

The Ampli1 ${ }^{\text {TM }}$ WGA procedure is based on a ligation-mediated PCR following a site-specific DNA digestion with a library of highly concentrated DNA, which can be employed for further targeted genetic analysis. The DNA from the isolated CTCs or WBCs was amplified using the Ampli1 ${ }^{\mathrm{TM}} \mathrm{kit}$ WGA (Silicon Biosystems) according to the manufacturer's instruction. Briefly, the isolated CTCs were thawed on ice and brought up to a volume of $1 \mu \mathrm{L}$ of PBS to perform all the reaction in same tube as following steps: cell lysis, DNA digestion, ligation, and primary PCR according to the procedure of the supplier resulting in final volume $50 \mu \mathrm{L}$ of WGA product. Genome integrity was evaluated using the Ampli 1-QC kit (Silicon Biosystems, Inc). Ampli 1-QC kit is a PCR assay which allows the simultaneous amplification of four different human genomic targets using $1 \mu \mathrm{L}$ of an Ampli1 ${ }^{\mathrm{TM}}$ WGA product. PCR products were visualized on a $1.5 \%$ agarose gel to determinate the genome integrity as previously described [22].

\subsection{TP53 and ESR1 Mutations in CTCS}

Amplified DNA from CTCs was used for TP53 and ESR1 mutations analysis which was performed by Sanger sequencing. The primers reverse 5'-GAAATCGGTAAGAGGTGGGC-3' and forward $5^{\prime}$-GCTTGCCACAGGTCTCCCCA-3' were used to amplify hot spot region in 
exon 6 of TP53 (R248). The primers reverse $5^{\prime}$-CCCCAACCCATAGACTGAG-3' and forward 5'-GCTAAGTGCTTTGGAGTTC-3' were used to amplify the exon 8 of ESR1 (K531E, V534E, P535H, L536R/Q, Y537N/C/S, D538G). PCR reactions were performed using the AmpliTaq-Gold Taq DNA polymerase (Applied Biosystems, Foster City, CA, USA) according to manufacturer's instructions. Both genes were amplified at $95{ }^{\circ} \mathrm{C}$ for $30 \mathrm{~s}$ as the denaturation, at $60{ }^{\circ} \mathrm{C}$ for TP53 and $57{ }^{\circ} \mathrm{C}$ for ESR 1 for $30 \mathrm{~s}$ as the annealing, and at $72{ }^{\circ} \mathrm{C}$ for $30 \mathrm{~s}$ as the primer extension for a total of 30 cycles. The amplified products were separated by electrophoresis on a $2 \%$ agarose $/ 1 \times$ TAE (Tris, acetic acid, EDTA) gel. The PCR products were cleaned using the Amicon Microcon PCR purification kit (EMD Millipore, Billerica, MA, USA). The purified PCR product were finally sequenced on the ABI PRISM ${ }^{\circledR}$ 3700 (Applied Biosystems) capillary genetic analyzer with the same primers in both directions.

Acknowledgments: The work reported in this study received supports from Thomas Jefferson University, The Inflammatory Breast Cancer Network Foundation, and ScreenCell.

Author Contributions: Massimo Cristofanilli, Zhaomei Mu, Naoual Benali-Furet and Georges Uzan conceived and designed the experiments; Zhaomei Mu, Naoual Benali-Furet, Anaëlle Znaty, Zhong Ye and Carmela Paolillo performed the experiments; Laura Austin, Chun Wang, Giovanna Rossi, Paolo Fortina, Hushan Yang contributed protocol/analysis tools; Zhaomei Mu, Massimo Cristofanilli, Naoual Benali-Furet and Georges Uzan analyzed the data and wrote the paper.

Conflicts of Interest: The authors declare no conflict of interest.

\section{References}

1. Torre, L.A.; Bray, F.; Siegel, R.L.; Ferlay, J.; Lortet-Tieulent, J.; Jemal, A. Global cancer statistics, 2012. CA Cancer J. Clin. 2015, 65, 87-108. [CrossRef] [PubMed]

2. Angela, T.; Cristofanilli, M. Molecular characterization and targeted therapeutic approaches in breast cancer. Breast Cancer Res. 2015. [CrossRef]

3. Krebs, M.G.; Metcalf, R.L.; Carter, L.; Brady, G.; Blackhall, F.H.; Dive, C. Molecular analysis of circulating tumour cells-biology and biomarkers. Nat. Rev. Clin. Oncol. 2014, 11, 129-144. [CrossRef] [PubMed]

4. Ignatiadis, M.; Lee, M.; Jeffrey, S.S. Circulating tumor cells and circulating tumor DNA: Challenges and opportunities on the path to clinical utility. Clin. Cancer Res. 2015, 21, 4786-4800. [CrossRef] [PubMed]

5. Allard, W.J.; Matera, J.; Miller, M.C.; Repollet, M.; Connelly, M.C.; Rao, C.; Tibbe, A.G.; Uhr, J.W.; Terstappen, L.W. Tumor cells circulate in the peripheral blood of all major carcinomas but not in healthy subjects or patients with nonmalignant diseases. Clin. Cancer Res. 2004, 10, 6897-6904. [CrossRef] [PubMed]

6. Riethdorf, S.; Wikman, H.; Pantel, K. Review: Biological relevance of disseminated tumor cells in cancer patients. Int. J. Cancer 2008, 123, 1991-2006. [CrossRef] [PubMed]

7. Cristofanilli, M.; Budd, G.T.; Ellis, M.J.; Stopeck, A.; Matera, J.; Miller, M.C.; Reuben, J.M.; Doyle, G.V.; Allard, W.J.; Terstappen, L.W.; et al. Circulating tumor cells, disease progression, and survival in metastatic breast cancer. N. Engl. J. Med. 2004, 351, 781-791. [CrossRef] [PubMed]

8. Bidard, F.C.; Peeters, D.J.; Fehm, T.; Nole, F.; Gisbert-Criado, R.; Mavroudis, D.; Grisanti, S.; Generali, D.; Garcia-Saenz, J.A.; Stebbing, J.; et al. Clinical validity of circulating tumour cells in patients with metastatic breast cancer: a pooled analysis of individual patient data. Lancet Oncol. 2014, 15, 406-414. [CrossRef]

9. Budd, G.T.; Cristofanilli, M.; Ellis, M.; Stopeck, A.; Borden, E.; Miller, M.C.; Matera, J.; Repollet, M.; Doyle, G.V.; Terstappen, L.W.; et al. Circulating tumor cells versus imaging-predicting overall survival in metastatic breast cancer. Clin. Cancer Res. 2006, 12, 6403-6409. [CrossRef] [PubMed]

10. Hayes, D.F.; Cristofanilli, M.; Budd, G.T.; Ellis, M.J.; Stopeck, A.; Miller, M.C.; Matera, J.; Allard, W.J.; Doyle, G.V.; Terstappen, L.W. Circulating tumor cells at each follow-up time point during therapy of metastatic breast cancer patients predict progression-free and overall survival. Clin. Cancer Res. 2006, 12, 4218-4224. [CrossRef] [PubMed]

11. Mego, M.; Mani, S.A.; Cristofanilli, M. Molecular mechanisms of metastasis in breast cancer-clinical applications. Nat. Rev. Clin. Oncol. 2010, 7, 693-701. [CrossRef] [PubMed]

12. Aktas, B.; Tewes, M.; Fehm, T.; Hauch, S.; Kimmig, R.; Kasimir-Bauer, S. Stem cell and epithelial-mesenchymal transition markers are frequently overexpressed in circulating tumor cells of metastatic breast cancer patients. Breast Cancer Res. 2009. [CrossRef] [PubMed] 
13. Papadaki, M.A.; Kallergi, G.; Zafeiriou, Z.; Manouras, L.; Theodoropoulos, P.A.; Mavroudis, D.; Georgoulias, V.; Agelaki, S. Co-expression of putative stemness and epithelial-to-mesenchymal transition markers on single circulating tumour cells from patients with early and metastatic breast cancer. BMC Cancer 2014. [CrossRef] [PubMed]

14. Adams, D.L.; Martin, S.S.; Alpaugh, R.K.; Charpentier, M.; Tsai, S.; Bergan, R.C.; Ogden, I.M.; Catalona, W.; Chumsri, S.; Tang, C.M.; et al. Circulating giant macrophages as a potential biomarker of solid tumors. Proc. Natl. Acad. Sci. USA. 2014, 111, 3514-3519. [CrossRef] [PubMed]

15. Alix-Panabieres, C.; Pantel, K. Challenges in circulating tumour cell research. Nat. Rev. Cancer 2014, 14, 623-631. [CrossRef] [PubMed]

16. Desitter, I.; Guerrouahen, B.S.; Benali-Furet, N.; Wechsler, J.; Jänne, P.A.; Kuang, Y.; Yanagita, M.; Wang, L.; Berkowitz, J.A.; Distel, R.J.; et al. A new device for rapid isolation by size and characterization of rare circulating tumor cells. Anticancer Res. 2011, 31, 427-441. [PubMed]

17. Chen, C.L.; Mahalingam, D.; Osmulski, P.; Jadhav, R.R.; Wang, C.M.; Leach, R.J.; Chang, T.C.; Weitman, S.D.; Kumar, A.P.; Sun, L.; et al. Single-cell analysis of circulating tumor cells identifies cumulative expression patterns of EMT-related genes in metastatic prostate cancer. Prostate 2013, 73, 813-826. [CrossRef] [PubMed]

18. Kulemann, B.; Pitman, M.B.; Liss, A.S.; Valsangkar, N.; Fernández-Del Castillo, C.; Lillemoe, K.D.; Hoeppner, J.; Mino-Kenudson, M.; Warshaw, A.L.; Thayer, S.P. Circulating tumor cells found in patients with localized and advanced pancreatic cancer. Pancreas 2015, 44, 547-550. [CrossRef] [PubMed]

19. El-Heliebi, A.; Kroneis, T.; Zöhrer, E.; Haybaeck, J.; Fischereder, K.; Kampel-Kettner, K.; Zigeuner, R.; Pock, H.; Riedl, R.; Stauber, R.; et al. Are morphological criteria sufficient for the identification of circulating tumor cells in renal cancer? J. Transl. Med. 2013. [CrossRef] [PubMed]

20. Coget, J.; Borrini, F.; Susman, S.; Sabourin, J.C. Colorectal carcinomas in 2013: The search for powerful prognostic markers is still on the go. Cancer Biomark. 2014, 14, 145-150. [PubMed]

21. Mascalchi, M.; Falchini, M.; Maddau, C.; Salvianti, F.; Nistri, M.; Bertelli, E.; Sali, L.; Zuccherelli, S.; Vella, A.; Matucci, M.; et al. Prevalence and number of circulating tumour cells and microemboli at diagnosis of advanced NSCLC. J. Cancer Res. Clin. Oncol. 2016, 142, 195-200. [CrossRef] [PubMed]

22. Polzer, B.; Medoro, G.; Pasch, S.; Fontana, F.; Zorzino, L.; Pestka, A.; Andergassen, U.; Meier-Stiegen, F.; Czyz, Z.T.; Alberter, B.; et al. Molecular profiling of single circulating tumor cells with diagnostic intention. EMBO Mol. Med. 2014, 30, 1371-1386. [CrossRef] [PubMed]

23. Vishnoi, M.; Peddibhotla, S.; Yin, W.; Scamardo, A.T.; George, G.C.; Hong, D.S.; Marchetti, D. The isolation and characterization of CTC subsets related to breast cancer dormancy. Sci. Rep. 2015. [CrossRef] [PubMed]

24. De Luca, F.; Rotunno, G.; Salvianti, F.; Galardi, F.; Pestrin, M.; Gabellini, S.; Simi, L.; Mancini, I.; Vannucchi, A.M.; Pazzagli, M.; et al. Mutational analysis of single circulating tumor cells by next generation sequencing in metastatic breast cancer. Oncotarget 2016. [CrossRef]

25. Robinson, D.R.; Wu, Y.M.; Vats, P.; Su, F.; Lonigro, R.J.; Cao, X.; Kalyana-Sundaram, S.; Wang, R.; Ning, Y.; Hodges, L.; et al. Activating ESR1 mutations in hormone-resistant metastatic breast cancer. Nat. Genet. 2013, 45, 1446-1451. [CrossRef] [PubMed]

26. Mu, Z.; Wang, C.; Ye, Z.; Austin, L.; Civan, J.; Hyslop, T.; Palazzo, J.P.; Jaslow, R.; Li, B.; Myers, R.E.; et al. Prospective assessment of the prognostic value of circulating tumor cells and their clusters in patients with advanced-stage breast cancer. Breast Cancer Res. Treat. 2015, 154, 563-571. [CrossRef] [PubMed]

27. Aceto, N.; Bardia, A.; Miyamoto, D.T.; Donaldson, M.C.; Wittner, B.S.; Spencer, J.A.; Yu, M.; Pely, A.; Engstrom, A.; Zhu, H.; et al. Circulating tumor cell clusters are oligoclonal precursors of breast cancer metastasis. Cell 2014, 158, 1110-1122. [CrossRef] [PubMed]

28. Paoletti, C.; Li, Y.; Muniz, M.C.; Kidwell, K.M.; Aung, K.; Thomas, D.G.; Brown, M.E.; Abramson, V.G.; Irvin, W.J., Jr.; Lin, N.U.; et al. Significance of circulating tumor cells in metastatic triple-negative breast cancer patients within a randomized, phase II trial: TBCRC 019. Clin. Cancer Res. 2015, 21, 2771-2779. [CrossRef] [PubMed]

29. Wu, Y.; Sarkissyan, M.; Vadgama, J.V. Epithelial-mesenchymal transition and breast cancer. J. Clin. Med. 2016. [CrossRef] [PubMed]

30. Kallergi, G.; Papadaki, M.A.; Politaki, E.; Mavroudis, D.; Georgoulias, V.; Agelaki, S. Epithelial to mesenchymal transition markers expressed in circulating tumour cells of early and metastatic breast cancer patients. Breast Cancer Res. 2011. [CrossRef] [PubMed] 
31. Armstrong, A.J.; Marengo, M.S.; Oltean, S.; Kemeny, G.; Bitting, R.L.; Turnbull, J.D.; Herold, C.I.; Marcom, P.K.; George, D.J.; Garcia-Blanco, M.A. Circulating tumor cells from patients with advanced prostate and breast cancer display both epithelial and mesenchymal markers. Mol. Cancer Res. 2011, 9, 997-1007. [CrossRef] [PubMed]

32. Kasimir-Bauer, S.; Hoffmann, O.; Wallwiener, D.; Kimmig, R.; Fehm, T. Expression of stem cell and epithelial-mesenchymal transition markers in primary breast cancer patients with circulating tumor cells. Breast Cancer Res. 2012. [CrossRef] [PubMed]

33. Barrière, G.; Riouallon, A.; Renaudie, J.; Tartary, M.; Rigaud, M. Mesenchymal and stemness circulating tumor cells in early breast cancer diagnosis. BMC Cancer 2012. [CrossRef] [PubMed]

34. Hamilton, G.; Rath, B.; Klameth, L.; Hochmair, M.J. Small cell lung cancer: Recruitment of macrophages by circulating tumor cells. Oncoimmunology 2015. [CrossRef] [PubMed]

35. Adams, D.L.; Adams, D.K.; Alpaugh, R.K.; Cristofanilli, M.; Martin, S.S.; Chumsri, S.; Tang, C.M.; Marks, J.R. Circulating cancer-associated macrophage-like cells differentiate malignant breast cancer and benign breast conditions. Cancer Epidemiol. Biomark. Prev. 2016, 25, 1037-1042. [CrossRef] [PubMed]

36. Smerage, J.B.; Barlow, W.E.; Hortobagyi, G.N.; Winer, E.P.; Leyland-Jones, B.; Srkalovic, G.; Tejwani, S.; Schott, A.F.; O'Rourke, M.A.; Lew, D.L.; et al. Circulating tumor cells and response to chemotherapy in metastatic breast cancer: SWOG S0500. J. Clin. Oncol. 2014, 32, 3483-3489. [CrossRef] [PubMed]

(C) 2016 by the authors; licensee MDPI, Basel, Switzerland. This article is an open access article distributed under the terms and conditions of the Creative Commons Attribution (CC-BY) license (http://creativecommons.org/licenses/by/4.0/). 